\title{
A 3D-scaffold of PLLA induces the morphological differentiation and migration of primary astrocytes and promotes the production of extracellular vesicles
}

\author{
FRANCESCO CARFI PAVIA $^{1^{*}}$, MARIA ANTONIETTA DI BELLA ${ }^{2 *}$, VALERIO BRUCATO ${ }^{1}$, VALERIA BLANDA $^{1}$, \\ FRANCESCA ZUMMO $^{3}$, ILENIA VITRANO ${ }^{1}$, CARLO MARIA DI LIEGRO ${ }^{3}$, \\ GIULIO GHERSI $^{3}$, ITALIA DI LIEGRO ${ }^{2}$ and GABRIELLA SCHIERA ${ }^{3}$ \\ ${ }^{1}$ Department of Engineering, University of Palermo, I-90128 Palermo; ${ }^{2}$ Department of Biomedicine, \\ Neurosciences and Advanced Diagnostics, University of Palermo, I-90133 Palermo; \\ ${ }^{3}$ Department of Biological Chemical and Pharmaceutical Sciences and Technologies, \\ University of Palermo, I-90128 Palermo, Italy
}

Received November 5, 2018; Accepted May 16, 2019

DOI: $10.3892 / \mathrm{mmr} .2019 .10351$

\begin{abstract}
The present study analyzed the ability of primary rat astrocytes to colonize a porous scaffold, mimicking the reticular structure of the brain parenchyma extracellular matrix, as well as their ability to grow, survive and differentiate on the scaffold. Scaffolds were prepared using poly-L-lactic acid (PLLA) via thermally-induced phase separation. Firstly, the present study studied the effects of scaffold morphology on the growth of astrocytes, evaluating their capability to colonize. Specifically, two different morphologies were tested, which were obtained by changing the polymer concentration in the starting solution. The structures were characterized by scanning electron microscopy, and a pore size of $20 \mu \mathrm{m}$ (defined as the average distance between the pore walls) was detected. For comparison, astrocytes were also cultured in the traditional $2 \mathrm{D}$ culture system that we have been using since 2003. Then the effects of different substrates, such as collagen I and IV, and fibronectin were analyzed. The results revealed that the PLLA scaffolds, coated with collagen IV, served as very good matrices for astrocytes, which were observed to adhere, grow and colonize the matrix, acquiring their typical morphology.
\end{abstract}

Correspondence to: Professor Italia Di Liegro, Department of Biomedicine, Neurosciences and Advanced Diagnostics, University of Palermo, Via del Vespro 129, I-90133 Palermo, Italy

E-mail: italia.diliegro@unipa.it

Dr Gabriella Schiera, Department of Biological Chemical and Pharmaceutical Sciences and Technologies, University of Palermo, Viale delle Scienze, ed. 16, I-90128 Palermo, Italy

E-mail: gabriella.schiera@unipa.it

${ }^{*}$ Contributed equally

Key words: neural tissue engineering, astrocytes, 3D cultures, poly-L-lactic acid scaffold, extracellular vesicles
In addition, under these conditions, they secreted extracellular vesicles (EVs) that were compatible in size with exosomes. Their ability to produce exosomes was also suggested by transmission electron microscopy pictures which revealed both EVs and intracellular structures that could be interpreted as multivesicular bodies. The fact that these cells were able to adapt to the PLLA scaffold, together with our previous results, which demonstrated that brain capillary endothelial cells can grow and differentiate on the same scaffold, could support the future use of 3D brain cell co-culture systems.

\section{Introduction}

Tissue engineering is a multidisciplinary biotechnological science, the aim of which is to produce in vitro (and then possibly in vivo) tissues resembling at best the original tissues, to be used for the therapeutic replacement/regeneration of damaged tissues, and as models for functional and toxicological in vitro studies.

In the attempt to construct suitable tissue models, a critical step is the setting of 3D-scaffolds that simulate the extracellular matrix (ECM) into which cells are normally embedded. Importantly, cell behavior is controlled by signals originating from the ECM, but the cells themselves are also the producers of the ECM. Therefore a suitable scaffold is expected to be metabolized by cells and is gradually substituted with ECM molecules that can then be synthesized and secreted.

In this context, the generation of 3D cultures of brain cells is of particular interest. Cells of the nervous system (including neurons, astrocytes, oligodendrocytes, pericytes, microglial cells and endothelial cells) form a highly complex system in vivo in which cells continuously exchange information in many ways, including through extracellular vesicles (EVs). EVs are comprised of different types of membrane structures, the primary types include: i) Ectosomes (or microvesicles) that bud directly from the plasma membrane; and ii) exosomes, which originate from the endosomal compartment via the exocytosis of multivesicular bodies (MVBs) (1). Given the 
difficulties encountered in discriminating the different classes of vesicles (2), they are often collectively called EVs. EVs contain proteins, nucleic acids, lipids and metabolites, and many of which are clearly enriched in EVs when compared with the producing cells, thereby suggesting the existence of specific sorting mechanisms (3). By releasing their contents to the ECM or directly into the surrounding cells, EVs have the potential to affect the structure and function of the brain, both in physiological and pathological conditions (4-7). EVs can also be involved in the distribution of pathological proteins, such as the prion protein (8), amyloid $\beta$ peptide (9) and the hyperphosphorylated tau protein (10).

In addition to their role in cell-to-cell communication (11), EVs are also present in biological fluids such as blood, saliva and urine, and it has been suggested that they and their contents could be used as biomarkers of specific pathologies (12).

We previously reported that both neurons (13) and astrocytes (14) are able to release EVs in 2D culture systems. However, in 2D-cultures the topology of the cell membranes could be different than in vivo. This could also mean a different distribution of membrane lipids and lipid-metabolizing enzymes. Given the suggested importance of these latter molecules in the specific sorting of molecules to EVs and in EV formation itself, it was reasoned that a 3D model could be more suitable to study these processes.

Previous studies have revealed that it is possible to carry out $3 \mathrm{D}$ astrocyte culture on substrates as different as hydrogel $(15,16)$, collagen (Coll) (17-19) and polymeric scaffolds $(20,21)$. For example, Hyysalo et al (22) demonstrated that astrocytes are able to grow on aligned poly( $\varepsilon$-caprolactone) nanofibers, spreading over them.

However, in all of the reported cases, the effect of the morphology of the adopted devices on cellular growth is still unclear. On the other hand, it is well known that the morphology of the scaffold markedly influences cell functions as well as tissue regeneration, which are both dependent on the size of the pores, as demonstrated in other cell types such as endothelial cells and chondrocytes, cultured on poly-L-lactic acid (PLLA) $(23,24)$. For these reasons, it is mandatory to rely on procedures that allow for the precise and reproducible control of the 3D support morphology, and, above all, of the pore size and porosity.

Among the possible techniques available to produce porous scaffolds, thermally-induced phase separation (TIPS) is probably one of the most versatile. This technique is based on the separation of the homogeneous polymer solution induced by a variation in temperature. Through TIPS, a porous structure with a high degree of interconnection can be obtained $(25,26)$. Furthermore, using a targeted temperature instead of time protocols it is possible to cover a wide range of pore dimensions (from 10 to $200 \mu \mathrm{m})(27,28)$.

Therefore, 3D-monocultures of brain capillary endothelial cells (BCECs), as previously reported (29), and astrocytes, which were analyzed in the present study, were tested on PLLA scaffolds with the aim to set a 3D-model to be enriched over time by co-culturing more than one brain cell type, in order to study in detail intercellular communications, especially those based on EVs. Specifically in the present in vitro study, PLLA scaffolds produced via TIPS were utilized as substrates for primary rat astrocyte $3 \mathrm{D}$ growth. Different scaffold morphologies and coatings were tested in order to evaluate their influence on astrocyte growth, morphology and EV production.

\section{Materials and methods}

Scaffold preparation and characterization. All of the porous devices employed for the 3D growth of neural cells are characterized by a very small average pore size ( $<30-40$ microns) (30-32). In order to achieve scaffolds with a low average pore size, the present study slightly modified the protocol described in a previous study (28). Specifically, experiments were performed at a demixing temperature of $0^{\circ} \mathrm{C}$ in order to ensure that a spinodal decomposition mechanism occurred (33). Two ternary solutions composed of PLLA Resomer ${ }^{\circledR}$ L 209 S (Evonik Industries), 1,4 dioxane (Sigma-Aldrich; Merck KGaA) and distilled water were prepared, with the same dioxane to water weight ratio of $87 / 13 \mathrm{wt} / \mathrm{wt}$ and different polymer concentrations (4 and $6 \% \mathrm{wt} / \mathrm{wt}$, respectively). Briefly, the solution was kept at $60^{\circ} \mathrm{C}$ and subsequently poured into a cylindrical high density polyethylene mold. Then the mold was sealed and placed in a thermal bath at $0^{\circ} \mathrm{C}$ for $10 \mathrm{~min}$. Quenching was conducted via immersion in an ethyl alcohol bath at a temperature of $-20^{\circ} \mathrm{C}$ for $15 \mathrm{~min}$ in order to freeze the structure.

The obtained samples were removed from the mold and washed in deionized water for $24 \mathrm{~h}$ to eliminate the residual dioxane. Then, the samples were dried in a vacuum at $30^{\circ} \mathrm{C}$ for $24 \mathrm{~h}$. Finally, smaller samples (diameter $5 \mathrm{~mm}$, thickness $1 \mathrm{~mm}$ ) were obtained by cutting the dried samples with a surgical blade. Scaffold pore size and topography were analyzed via scanning electron microscopy (SEM; Phenom Pro X, Phenom-World; Thermo Fisher Scientific, Inc.) at $5 \mathrm{kV}$ along the cross-section. Astrocytes were seeded on both types of scaffold and, at well-defined culture times, cell proliferation tests were conducted.

Cells and cell culture. The present study did not use animals as the astrocytes used had already been isolated from the brain cortices of 2-day old Wistar newborn rats (Harlan, Udine, Italy), and frozen in a solution containing $93 \%$ heat-inactivated fetal calf serum (FCS) and 7\% dimethyl-sulfoxide (both from Sigma-Aldrich; Merck KGaA), as previously described (34).

Astrocytes were thawed and cultured in DMEM/Ham's F-12 (2/1), supplemented with $10 \%$ heat-inactivated FCS (Sigma-Aldrich; Merck KGaA), and 100,000 units penicillin, $100 \mathrm{mg}$ streptomycin, and $250 \mu \mathrm{g}$ amphotericin B (Sigma-Aldrich; Merck KGaA) per liter. The cells were then maintained in humidified $5 \% \mathrm{CO}_{2} / 95 \%$ air, at $37^{\circ} \mathrm{C}$. To assess astrocyte purity, cells were cultured on coverslips, fixed with $96 \%$ ethanol on ice for $10 \mathrm{~min}$ and permeabilized for $5 \mathrm{~min}$ with $0.1 \%$ Triton X-100 in PBS. Cells were then incubated with polyclonal rabbit anti-glial fibrillary acidic protein (GFAP) antibodies (Sigma-Aldrich; Merck KGaA; cat. no. G9269; used at 1:200 dilution).

Subconfluent cultures were plated on scaffolds (100.000/scaffold; 5,000 cells/ $\mu 1$ of medium), previously sterilized with $70 \%$ ethanol in a vacuum for $24 \mathrm{~h}$ and pretreated for $1 \mathrm{~h}$ with Coll type I (Coll I; final concentration $1 \mu \mathrm{g} / \mu \mathrm{l}$; Sigma-Aldrich; Merck KGaA) in $0.01 \mathrm{M} \mathrm{CH}_{3} \mathrm{COOH}$, or Coll 
type IV (Coll IV; Sigma-Aldrich; Merck KGaA; $31 \mu \mathrm{g} / \mu \mathrm{l}$ ) in $0.05 \mathrm{~N} \mathrm{HCl}$, or with fibronectin $(0.05 \mu \mathrm{g} / \mathrm{ml})$ in Ham's F-12.

After incubation at $37^{\circ} \mathrm{C}$ and $5 \% \mathrm{CO}_{2}$ for 90 min to promote cell adhesion (35-37), each scaffold was transferred to a well of a 24-well plate and fresh medium was added.

Immunofluorescence. Cells were fixed in $96 \%$ ethanol, and immunostained with rabbit anti-GFAP antibodies (Sigma-Aldrich; Merck KGaA; cat. no. G9269; used at 1:200 dilution). The secondary antibody was rhodamine-isothiocyanate-conjugated anti-rabbit-IgG (Sigma-Aldrich; Merck KGaA; cat. no. T6778; used at a 1:100 dilution). Nuclei were stained with 4',6-diamidino-2-phenylindole dihydrochloride (H1200; Vector Laboratories, Inc.). Cells were finally observed under a fluorescence microscope (Olympus BX-50).

Cell proliferation assay. Cell proliferation on scaffolds was evaluated via Cell Counting Kit-8 (CCK8; Sigma-Aldrich; Merck KGaA); a sensitive colorimetric kit containing WST-8, a salt reduced by mitochondrial dehydrogenases to orange formazan, used to evaluate the absorbance at $450 \mathrm{~nm}$. At each time-point, scaffolds were transferred into other wells and each sample was incubated at $37^{\circ} \mathrm{C}$ and $5 \% \mathrm{CO}_{2}$ for $3 \mathrm{~h}$ with $500 \mu \mathrm{l}$ of the 1:10 diluted reagent in fresh medium. After incubation, the medium was collected and analyzed with a spectrophotometer at an absorbance of $450 \mathrm{~nm}$. The assays were carried out in triplicate for each time-point. Non-seeded scaffolds were used as the negative controls in each measurement.

Viability assay. The general condition of cells was evaluated by acridine orange/ethidium bromide $(\mathrm{AO} / \mathrm{EtBr})$ staining, using fluorescence microscopy (Olympus BX-50), in order to identify apoptotic and/or necrotic cells. Cells were washed with PBS and stained with $\mathrm{AO} / \mathrm{EtBr}$ solution (concentration of each compound: $100 \mu \mathrm{g} / \mathrm{ml}$ in PBS). Counting of viable cells was performed after dividing each picture into quarters. Cells in each quarter were counted by two different operators. Finally, the values were used to calculate a mean value.

Transmission electron microscopy (TEM). For ultrastructure evaluation with a TE microscope, cells plated on scaffolds were placed for $1 \mathrm{~h}$ at $4^{\circ} \mathrm{C}$ in $4 \%$ glutaraldehyde buffered with $0.05 \mathrm{M}$ sodium cacodylate ( $\mathrm{pH} 7.3$ ), followed by post-fixation in $1 \%$ osmium tetroxide. Subsequently, after rinsing, all specimens were progressively dehydrated in ethanol solutions, cleared in propylene oxide and embedded in Epon resin. Thin sections were stained and examined in a Jeoll 1400 TE microscope operated at $80 \mathrm{kV}$.

SEM. Seeded scaffolds were fixed in $4 \%$ glutaraldehyde for 30 min at $4^{\circ} \mathrm{C}$, rinsed in PBS and finally dehydrated through a graded series of ethanol $(15,30,50,70,90$ and $100 \%$, for 3 min each). After complete dehydration, the scaffolds were mounted on an aluminum stub, coated in gold and observed using SEM (Phenom Pro X, Phenom-World; Thermo Fisher Scientific, Inc.) at an accelerating voltage of $10 \mathrm{kV}$.

Statistical analysis. All of the experiments were repeated three times for each time-point. Data were expressed as the mean \pm standard deviation. Statistical analyses were conducted using GraphPad Prism software version 8.0 (GraphPad Software, Inc.). Multiple comparisons were assessed by one way analysis of variance with post hoc Bonferroni multiple analysis and for comparisons between two groups data were analyzed by Student's t-test. $\mathrm{P}<0.05$ was considered to indicate a statistically significant difference.

\section{Results}

Fig. 1 presents the morphologies of the resulting scaffolds. Although in both cases porous structures were obtained, evident differences in terms of morphology were detected between the two types of samples. As expected, both samples presented a very low average pore size, but a higher level of pore interconnection was observed in the $6 \%$ samples when compared with the $4 \%$ group. At a higher magnification (Fig. 1C and D), it is clearly visible that the pore walls of the $6 \%$ scaffolds are considerably thinner and, consequently, had a more open structure. On the other hand, when observing the pore morphology of the $4 \%$ samples, it would seem that nucleation and growth mechanism have occurred.

Fig. 1E presents the absorbance values of astrocytes grown on the two different types of scaffolds at the different time-points analyzed. When considering the whole period (except for T0), the number of cells on the $6 \%$ scaffold was higher when compared with the $4 \%$ scaffold. Based on this experimental evidence, the present study utilized the $6 \%$ scaffolds for the subsequent studies and analyses.

A preliminary analysis was also conducted to evaluate which substrate was the most suitable for the assessment of the adhesion and growth of astrocytes on the scaffolds. The low concentration of astrocytes and their non-homogeneous distribution on the scaffolds pretreated with Coll I (data not shown), together with the fact that the ECM of the nervous tissue is rich in Coll IV and Fibronectin (FN), led to the selection of the latter substrates for use in the subsequent experiments.

To verify whether the scaffolds coated with Coll IV or FN provided adequate support to the cells, the present study evaluated the cell proliferation by CCK8 assay (Fig. 2) and cell viability by $\mathrm{AO} / \mathrm{EtBr}$ staining (Fig. 3). The analysis of the growth curve evidenced that astrocytes adapted better on Coll IV than on FN. Images taken at various time-points revealed that the cells were viable over a time interval of 22 days in culture (Fig. 3). Furthermore, a preference for Coll IV, compared to FN, was also visible; cell viability on Coll IV was higher at all of the time-points (for example:

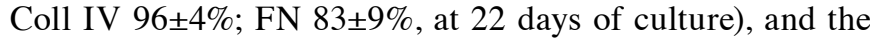
differences were significant $(\mathrm{P}<0.01)$. Astrocyte morphology on the PLLA scaffolds was also visualized by TEM. The images obtained confirmed that the cells colonized inside the porous matrices (Fig. 4A), although those that remained on the surface were also abundant (Fig. 4B).

Electron microscopy images provided further evidence of cell attachment onto the scaffold. Cells appeared well differentiated with their typical elongated shape and long processes (Figs. 4B and 5A). The cell body contained an irregularly round or oval nucleus, and the cytoplasm around the nucleus was abundant. The nucleoplasm of astrocytes was finely granular and of moderate density. It was evenly 

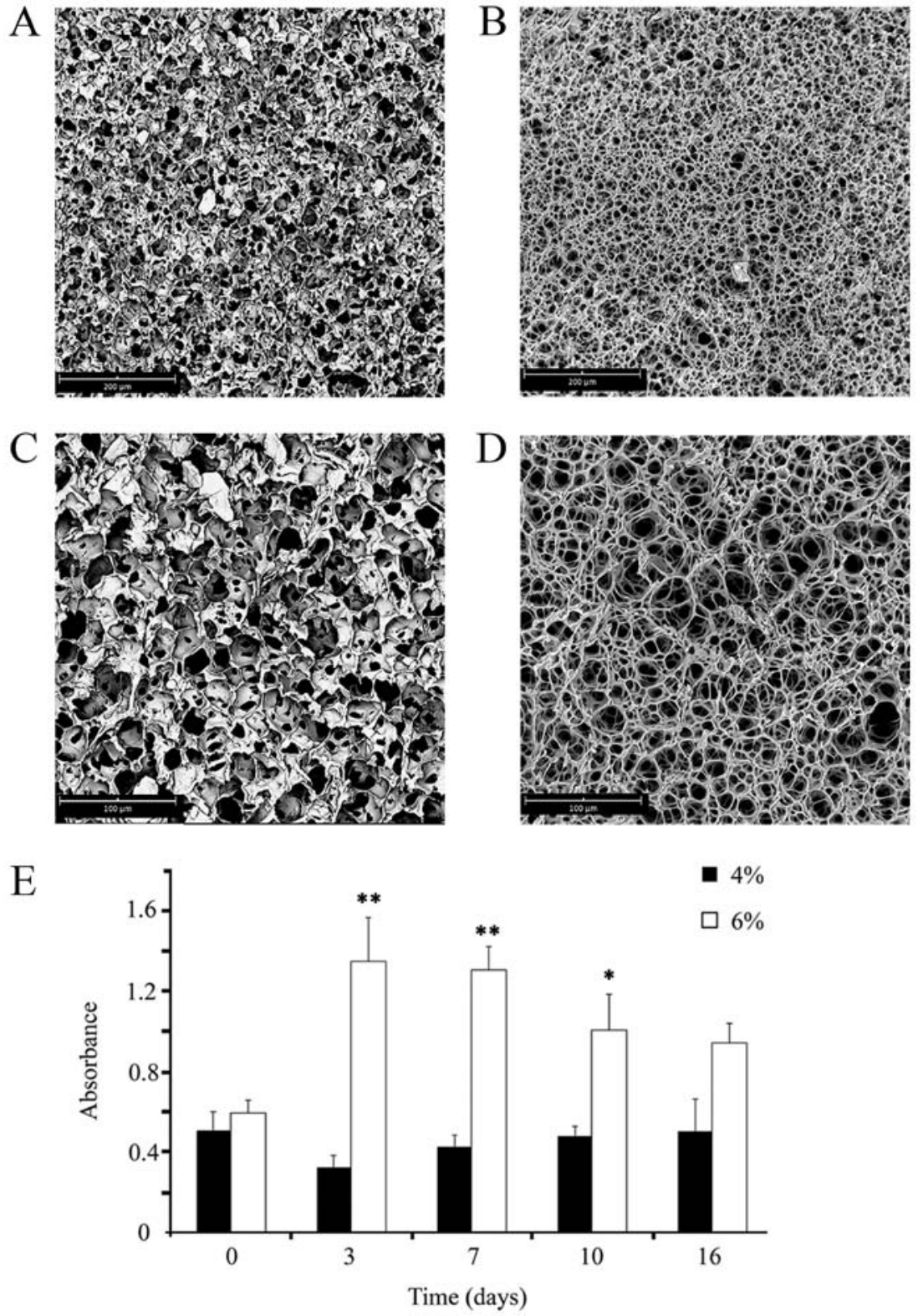

Figure 1. Scanning electron microscopy micrographs of the produced Poly-L-lactic acid scaffolds. The $4 \%$ scaffold at a (A) lower and (C) higher magnification (magnification, $\mathrm{x} 400$ and $\mathrm{x} 800$, respectively). The $6 \%$ scaffold at a (B) lower and (D) higher magnification (magnification, $\mathrm{x} 400$ and $\mathrm{x} 800$, respectively). Scale bars, (A and B) $200 \mu \mathrm{m}$, and (C and D) $100 \mu \mathrm{m}$. (E) Cell proliferation evaluation. Astrocytes were grown in the different scaffolds, at the indicated time-points, proliferation was evaluated by Cell Counting Kit- 8 assay. ${ }^{*} \mathrm{P}<0.05$ and ${ }^{* *} \mathrm{P}<0.01$ vs. $0 \mathrm{~h}$.

distributed through the nucleus, except for at the edge of the nuclear profile where it aggregated into clumps just under the nuclear membrane (Fig. 4B).

In the TEM micrographs, migration into the scaffold was easily detectable. Astrocytes can be seen throughout the homogenously distributed pores between polymer fibers. The interaction between the cells and scaffold as well as the star-like shape of the cells are visible in Fig. 5. At the same time, astrocytes formed intercellular junctions, including contacts between cell processes from distal astrocytes (arrows in Figs. 4 and 5).

Astrocyte morphology was also analyzed by staining the cells with antibodies against GFAP, an astrocyte-specific member of the intermediate filament family of proteins (Fig. 6). After 20 days of culture, the astrocytes began to assume their classic 'starry' morphology, with longer and thinner extensions,

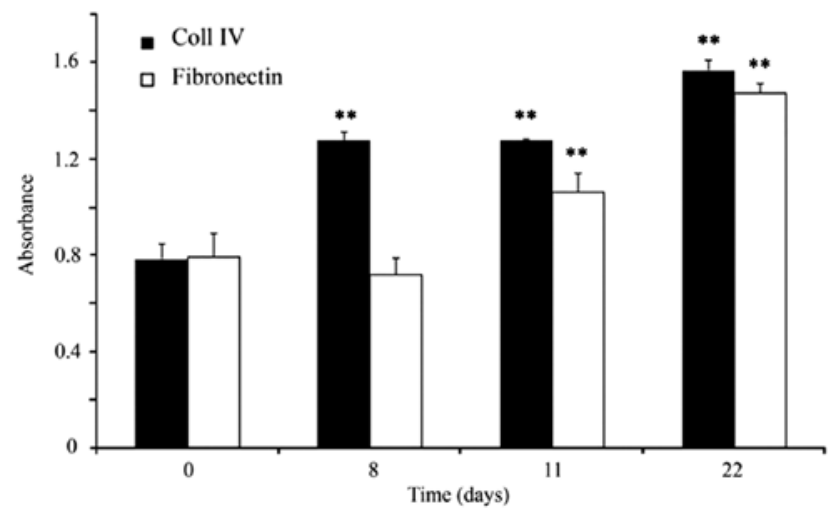

Figure 2. Cell proliferation assay. At the indicated time-points, the proliferation rate was evaluated by Cell Counting Kit- 8 assay; astrocytes were grown in $6 \%$ scaffolds coated with either Coll IV or FN. ${ }^{* *} \mathrm{P}<0.01$ vs. 0 h. Coll, collagen; FN, fibronectin. 
A

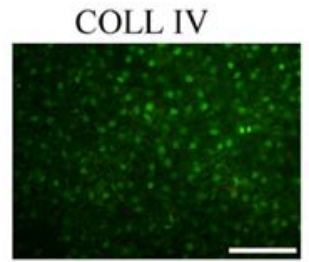

11

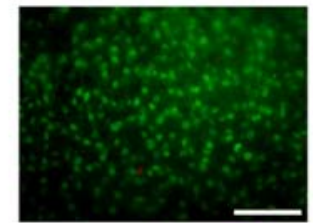

15

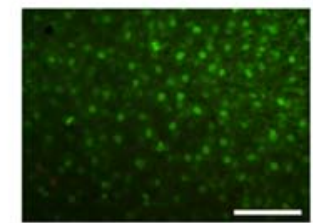

22
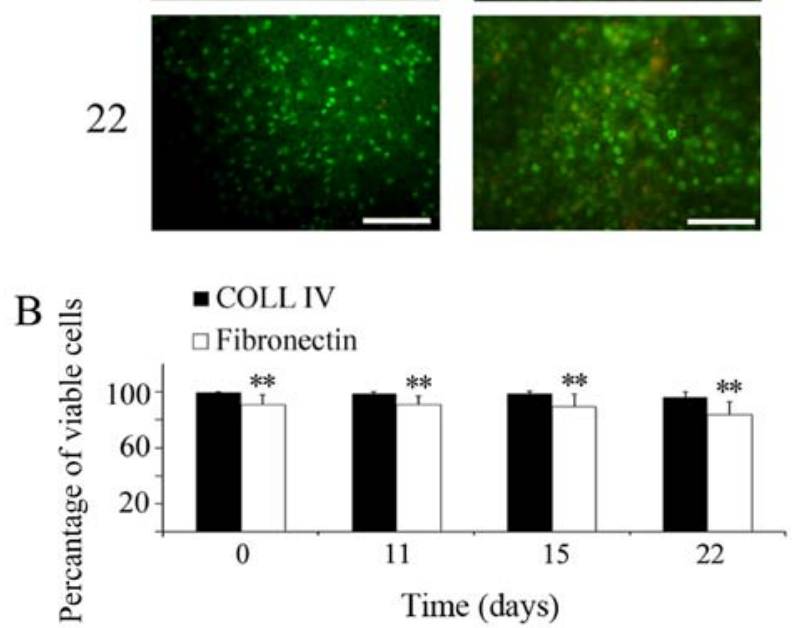

Figure 3. Cell viability evaluation. (A) Acridine orange/ethidium bromide cell staining on different days of culture $(0,11,15$ and 22 days); cells were plated on Coll IV or FN. Scale bars, $100 \mu \mathrm{m}$. (B) Percentage of viable cells on the different days of culture. Dark bars present the cells plated on Coll IV; white bars indicate the cells plated on FN. ${ }^{* *} \mathrm{P}<0.01$, FN vs. Coll IV at each stage. Coll, collagen; FN, fibronectin.

as it normally occurs in vivo (Fig. 6B). This phenotype is especially evident if the cells are kept in culture for a sufficiently long period of time (20-25 days). Interestingly, when grown in 2D, astrocytes maintain a more flattened shape, less similar to the in vivo shape (Fig. 6A).

A final important point was the observation that astrocytes grown on the 3D PLLA scaffold were able to produce EVs, as shown by both TEM and SEM analyses (Figs. 7 and 8). In Fig. 7A-D, some invaginations of the plasma membrane and small vesicles adjacent to the cell surface, or immediately outside the cell, were observed. In addition, intracellular membrane-bound bodies known as MVBs, with vesicles inside were clearly identifiable (Fig. 7B, arrow). The production of vesicles was also evident in the SEM analyses (Fig. 8).

\section{Discussion}

In the last few decades it has become more and more accepted that glial cells have more functions than expected. Astrocytes, in particular, contribute to the majority of neuronal activities,
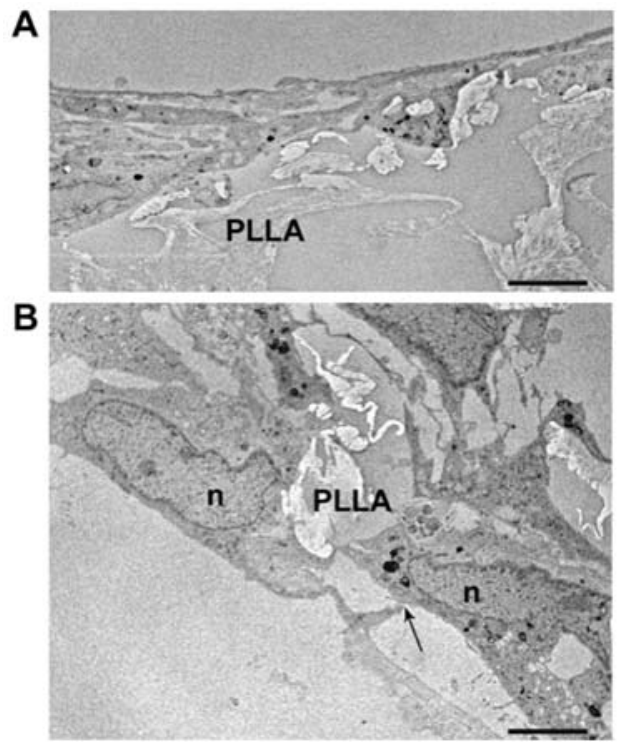

Figure 4. Representative transmission electron microscopy pictures of the ultra-thin sections. (A) Longitudinal- and (B) transversal- sections demonstrating cell attachment onto the scaffold. The astrocytes present extended cellular processes with points of contact (indicated by arrows). $n$, indicates the nucleus. Scale bars, (A) $6 \mu \mathrm{m}$ and (B) $5 \mu \mathrm{m}$. PLLA, Poly-L-lactic acid.
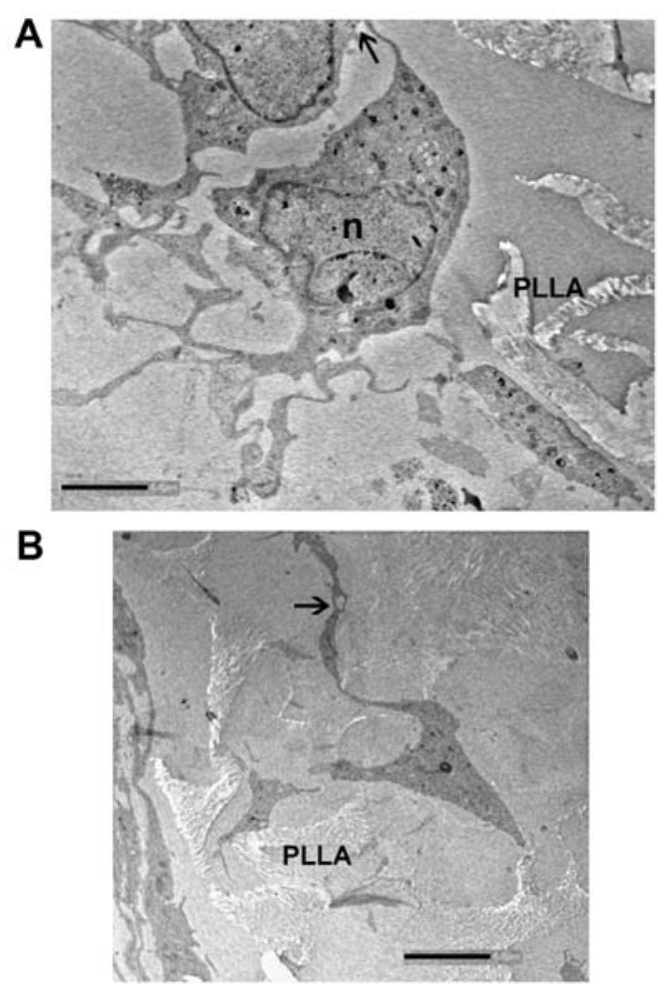

Figure 5. Electron micrographs of astrocytes that are (A) completely integrated or (B) migrating into the structure of the scaffold. Direct contacts between the astrocytes and the surface of the scaffold can be seen. The cells exhibit the classical appearance with branched processes touching each other (indicated by arrows). $\mathrm{n}$, indicates the nucleus. Scale bars, (A) $4 \mu \mathrm{m}$ and (B) $5 \mu \mathrm{m}$. PLLA, Poly-L-lactic acid.

from recapturing neurotransmitters to the transfer of critical metabolites, such as lactate (38). Interestingly, astrocytes do not behave like single cells, but, thanks to a net of long intercellular contacts based on gap junction channels $(39,40)$ 

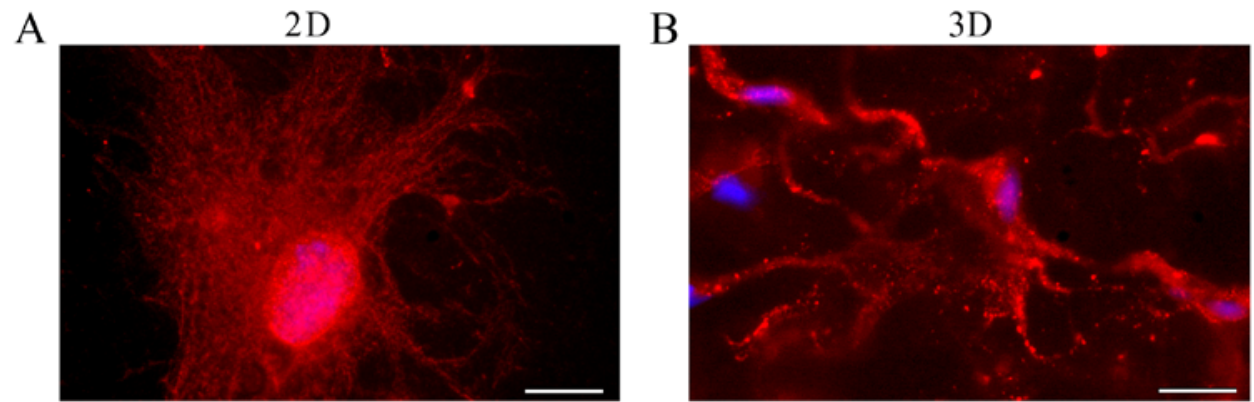

Figure 6. Astrocytes cultured on two geometrically different substrates: (A) On glass (2D culture) or (B) on Poly-L-lactic acid scaffolds (3D culture). Cells were immunostained with anti-glial fibrillary acidic protein antibodies. Scale bars, $10 \mu \mathrm{m}$.

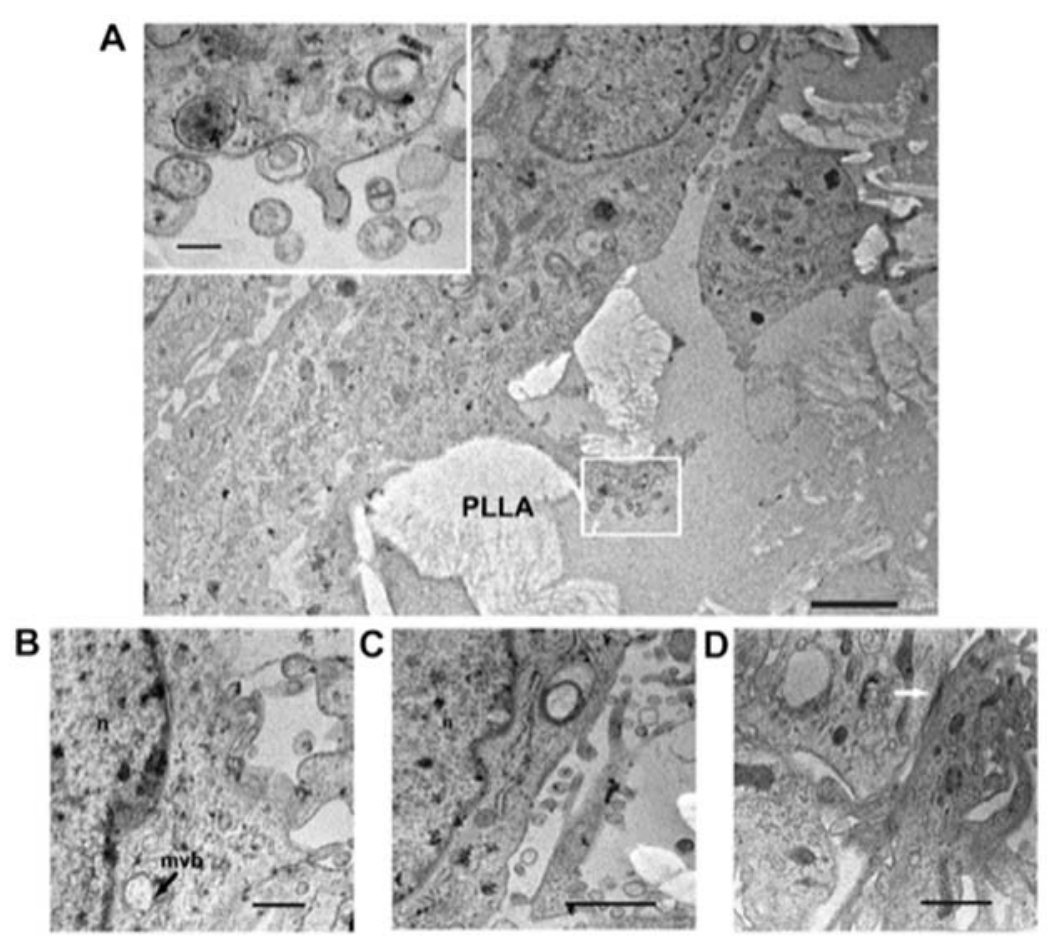

Figure 7. Transmission electron microscopy pictures presenting astrocytes releasing extracellular vesicles. (A) Image showing different cells that migrated through the scaffold and their cellular processes around the Poly-L-lactic acid fibers. Details within the boxed white area are reported in the inset, where different single or double vesicles can be observed at higher magnification. (B) A multivesicular body can be seen in the cytoplasm (indicated by a black arrow). (C) Micrograph of a portion of the cellular surface with abundant vesicles in the space. (D) The plasma membrane was deeply folded; the arrow indicates an electron-dense intercellular junction between lateral plasma membranes. $\mathrm{n}$, indicates the nucleus Scale bars: (A) $2.0 \mu \mathrm{m}$; (B) $500 \mathrm{~nm}$ (inset, $200 \mathrm{~nm}$ ); (C and D) $1.0 \mu \mathrm{m}$. PLLA, Poly-L-lactic acid.

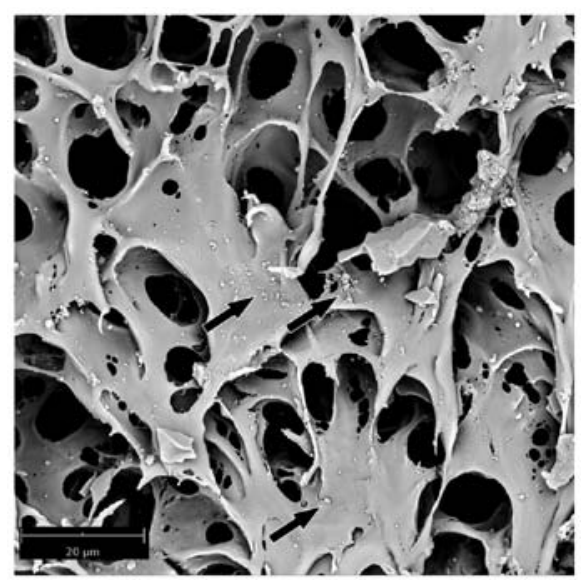

Figure 8. Scanning electron microscopy micrograph of astrocyte-seeded scaffolds. Microvesicles are indicated by black arrows. Scale bar, $20 \mathrm{~mm}$. formed by connexins (41), they seem to constitute networks embracing neurons; these networks may control many aspects of neuronal metabolism, such as ion and water transport, and energy metabolite exchange, probably in a synaptic activity-dependent manner. Notably, neuron-glial cell communications are possibly also mediated in both directions by EVs (5). Most importantly, vesicle production by glial cells seems to be regulated by neurotransmission (42). To date, many reports have suggested that astrocytes cultured under $2 \mathrm{D}$ conditions, although they are able to attach to the substrate, to grow and to express the astrocyte-specific GFAP, do not assume all of the morphological and functional properties of astrocytes in vivo. For this reason, the present study decided to set a 3D system more similar to the tridimensional environment of the brain. In particular, a PLLA scaffold was used as many cell types have already been shown to be able to grow on 
this substrate and to metabolize it (43). The PLLA matrix was first prepared starting from two different concentrations of polymer in the solution. At different initial concentrations, the polymers obtained showed different morphologies. Scaffolds with pores of an average size of $<20 \mu \mathrm{m}$, formed from a $6 \%$ starting solution, had the best effect on astrocyte survival and adaptation.

Another set of experiments aimed to identify the biological macromolecules able to improve cell adhesion on the scaffolds. To this end, immediately before cell seeding, the scaffolds were treated with two different substrates (Coll IV and FN). The results demonstrated that the best degree of adhesion could be obtained with Coll IV-coated scaffolds, though FN also had a good effect on astrocyte survival. These results agree with a previous study, which demonstrated that astrocytes showed only moderate affinity for surfaces covered with FN (44). In addition, in another study Coll was demonstrated to support both initial adhesion and the growth of astrocytes because of its favorable gelation properties, the presentation of bioactive adhesive sites, and the ability to be remodeled by astrocytes (18).

Accordingly, the present study revealed that astrocytes adhere to Coll IV-coated scaffolds, and are able to grow on them and to colonize the matrix, acquiring a typical star-like morphology. In addition, they formed cell contacts both at the level of the cell bodies, and among their long and thin processes.

In addition, they also secrete EVs, compatible in size with exosomes. Their ability to produce exosomes was demonstrated by both TEM and SEM analyses, which revealed EVs and intracellular MVBs. This observation is of the most importance as it confirms that, as proposed years ago (14), astrocytes can produce EVs even in cell culture. It is now well recognized that all of the brain cell types release exosomes in vivo $(5,45,46)$, and that these particles can also be transported across the blood-brain barrier (47). At present, we do not know whether the amount of EVs produced by astrocytes in the scaffold was comparable with the amount of EVs released in $2 \mathrm{D}$ cultures nor whether it was comparable with the amount of EVs released in vivo by comparable numbers of cells; similarly, we currently do not know the composition of EVs released from astrocytes in our culture system. However, once established, a 3D scaffold such as that described in the present study, appears to work well for astrocytes; future experiments are already in progress, aiming to compare the rate of production and the components of astrocyte-derived EVs, in vivo and in culture. These experiments will be run in parallel with the attempt to co-culture astrocytes with other brain cell types. In our opinion, it is unlikely that the properties of EVs released from astrocytes cultured alone are completely comparable with those of EVs produced in vivo; many researchers have already proposed that EV properties are as a result of continuous cross-talk between all of the different brain cell types (48).

For the development of these complex systems, the availability of a stable 3D model for brain cell culture was an essential starting point. The use of polymeric structures as substrates able to drive cell behavior and to reproduce tissue environment has widely diffused in the last few years (49). The present study proposes that PLLA scaffolds constitute a good model for the 3D growth of astrocytes. The main advantage of using PLLA is that it relies on its properties, including biocompatibility, processability, and degradation rates. In addition, this polymer is characterized by long biodegradation times ( 1 year) $(28,50)$, that could allow for the performance of long-term in vitro tests. As a further contribution to the field, the present study presents a simple and feasible modelling method which allows to tune the properties of the scaffold in terms of pore dimensions. However, the model requires further improvements and upgrading in further studies.

In conclusion, the results of the present study together with those obtained in the previous analysis on BCECs (29), suggest that the chosen conditions could be a good starting point for the preparation of 3D brain cell co-culture systems, more suitable for studying brain cell-cell interaction routes, including the physiology of EV production and delivery.

\section{Acknowledgements}

Not applicable.

\section{Funding}

The present study was supported by the Italian Ministry of Education, Universities and Research (grant no. PJ_RIC_ FFABR_2017_160958).

\section{Availability of data and materials}

The datasets used and/or analyzed during the current study are available from the corresponding author on reasonable request.

\section{Authors' contributions}

$\mathrm{VBl}, \mathrm{FZ}$ and IV produced the scaffold and carried out the cell seeding experiments. MADB produced the TEM images and contributed to the analysis of the results. FCP performed all of the SEM experiments. GS performed the fluorescence experiments. CMDL, GG and VBr contributed to the analysis of the results. FCP, GS, CMDL and IDL conceived and designed the study, and contributed to the analysis of the results. The manuscript was written by IDL, GS and FCP with close consultation with all of the other authors. All authors have approved the final version of the manuscript.

\section{Ethics approval and consent to participate}

Not applicable.

\section{Patient consent for publication}

Not applicable.

\section{Competing interests}

The authors declare that they have no competing interests.

\section{References}

1. Cocucci E and Meldolesi J: Ectosomes and exosomes: Shedding the confusion between extracellular vesicles. Trends Cell Biol 25: 364-372, 2015. 
2. Mateescu B, Kowal EJ, van Balkom BW, Bartel S, Bhattacharyya SN, Buzás EI, Buck AH, de Candia P, Chow FW, Das S, et al: Obstacles and opportunities in the functional analysis of extracellular vesicle RNA-an ISEV position paper. J Extracell Vesicles 6: 1286095, 2017.

3. Di Liegro CM, Schiera G and Di Liegro I: Extracellular vesicle-associated RNA as a carrier of epigenetic information. Genes (Basel) 8: E240, 2017.

4. Schiera G, Di Liegro CM, Saladino P, Pitti R, Savettieri G, Proia $\mathrm{P}$ and Di Liegro I: Oligodendroglioma cells synthesize the differentiation-specific linker histone H1.0; and release it into the extracellular environment through shed vesicles. Int J Oncol 43: 1771-1776, 2013.

5. Schiera G, Di Liegro CM and Di Liegro I: Extracellular membrane vesicles as vehicles for brain cell-to-cell interactions in physiological as well as pathological conditions. Biomed Res Int 2015: 152926, 2015

6. Schiera G, Di Liegro CM, Puleo V, Colletta O, Fricano A, Cancemi P, Di Cara G and Di Liegro I: Extracellular vesicles shed by melanoma cells contain a modified form of $\mathrm{H} 1.0$ linker histone and H1.0 mRNA-binding proteins. Int J Oncol 49: 1807-1814, 2016

7. Maas SLN, Breakefield XO and Weaver AM: Extracellular vesicles: Unique intercellular delivery vehicles. Trends Cell Biol 27: 172-188, 2017.

8. Vella LJ, Sharples RA, Nisbet RM, Cappai R and Hill AF: The role of exosomes in the processing of proteins associated with neurodegenerative diseases. Eur Biophys J 37: 323-332, 2008.

9. Rajendran L, Honsho M, Zahn TR, Keller P, Geiger KD, Verkade P and Simons K: Alzheimer's disease beta-amyloid peptides are released in association with exosomes. Proc Natl Acad Sci USA 103: 11172-11177, 2006.

10. Saman S, Kim WH, Raya M, Visnick Y, Miro S, Saman S, Jackson B, McKee AC, Alvarez VE, Lee NC and Hall GF: Exosome-associated tau is secreted in tauopathy models and is selectively phosphorylated in cerebrospinal fluid in early Alzheimer disease. J Biol Chem 287: 3842-3849, 2012.

11. Camussi G, Deregibus MC, Bruno S, Cantaluppi V and Biancone L: Exosomes/microvesicles as a mechanism of cell-to-cell communication. Kidney Int 78: 838-848, 2010

12. Rennert RC, Hochberg FH and Carter BS: ExRNA in biofluids as biomarkers for brain tumors. Cell Mol Neurobiol 36: 353-360, 2016.

13. Schiera G, Proia P, Alberti C, Mineo M, Savettieri G and Di Liegro I: Neurons produce FGF2 and VEGF and secrete them at least in part by shedding extracellular vesicles. J Cell Mol Med 11: 1384-1394, 2007

14. Proia P, Schiera G, Mineo M, Ingrassia AM, Santoro G, Savettieri G and Di Liegro I: Astrocytes shed extracellular vesicles that contain fibroblast growth factor- 2 and vascular endothelial growth factor. Int J Mol Med 21: 63-67, 2008

15. Knight VB and Serrano EE: Hydrogel scaffolds promote neural gene expression and structural reorganization in human astrocyte cultures. PeerJ 5: e2829, 2017.

16. Shi W, Huang CJ, Xu XD, Jin GH, Huang RQ, Huang JF, Chen YN, Ju SQ, Wang Y, Shi YW, et al: Transplantation of RADA16-BDNF peptide scaffold with human umbilical cord mesenchymal stem cells forced with CXCR4 and activated astrocytes for repair of traumatic brain injury. Acta Biomater 45 247-261, 2016

17. Katiyar KS, Winter CC, Struzyna LA, Harris JP and Cullen DK Mechanical elongation of astrocyte processes to create living scaffolds for nervous system regeneration. J Tissue Eng Regen Med 11: 2737-2751, 2017.

18. Winter CC, Katiyar KS, Hernandez NS, Song YJ, Struzyna LA, Harris JP and Cullen DK: Transplantable living scaffolds comprised of micro-tissue engineered aligned astrocyte networks to facilitate central nervous system regeneration. Acta Biomater 38: 44-58, 2016.

19. Führmann T, Hillen LM, Montzka K, Wöltje M and Brook GA Cell-Cell interactions of human neural progenitor-derived astrocytes within a microstructured 3D-scaffold. Biomaterials 31 : $7705-7715,2010$

20. Ugbode CI, Hirst WD and Rattray M: Astrocytes grown in alvetex ${ }^{\circledR}$ three dimensional scaffolds retain a non-reactive phenotype. Neurochem Res 41: 1857-1867, 2016.

21. Lau CL, Kovacevic M, Tingleff TS, Forsythe JS, Cate HS, Merlo D, Cederfur C, Maclean FL, Parish CL, Horne MK, et al: 3D Electrospun scaffolds promote a cytotrophic phenotype of cultured primary astrocytes. J Neurochem 130: 215-226, 2014.
22. Hyysalo A, Ristola M, Joki T, Honkanen M, Vippola M and Narkilahti S: Aligned poly( $\varepsilon$-caprolactone) nanofibers guide the orientation and migration of human pluripotent stem cell-derived neurons, astrocytes, and oligodendrocyte precursor cells in vitro. Macromol Biosci 17, 2017.

23. Conoscenti G, Schneider T, Stoelzel K, Carfì Pavia F, Brucato V, Goegele C, La Carrubba V and Schulze-Tanzil G: PLLA scaffolds produced by thermally induced phase separation (TIPS) allow human chondrocyte growth and extracellular matrix formation dependent on pore size. Mater Sci Eng C Mater Biol Appl 80: 449-459, 2017.

24. Narayan D and Venkatraman SS: Effect of pore size and interpore distance on endothelial cell growth on polymers. J Biomed Mater Res A 87: 710-718, 2008.

25. Carfì Pavia F, Palumbo FS, La Carrubba V, Bongiovì F, Brucato V, Pitarresi G and Giammona G: Modulation of physical and biological properties of a composite PLLA and polyaspartamide derivative obtained via thermally induced phase separation (TIPS) technique. Mater Sci Eng C Mater Biol Appl 67: 561-569, 2016.

26. Carfì Pavia F, La Carrubba V and Brucato V: Polymeric scaffolds based on blends of poly-1-lactic acid (PLLA) with poly-d-l-lactic acid (PLA) prepared via thermally induced phase separation (TIPS): Demixing conditions and morphology. Polym Bull 70: 563-578, 2013.

27. Mannella GA, Conoscenti G, Carfì Pavia F, La Carrubba V and Brucato V: Preparation of polymeric foams with a pore size gradient via Thermally Induced Phase Separation (TIPS). Mater Lett 160: 31-33, 2015.

28. Carfì Pavia F, La Carrubba V, Piccarolo S and Brucato V: Polymeric scaffolds prepared via thermally induced phase separation: Tuning of structure and morphology. J Biomed Mater Res A 86: 459-466, 2008.

29. Di Bella MA, Zummo F, Carfì Pavia F, Brucato VM, Di Liegro I and Schiera G: Migration of brain capillary endothelial cells inside poly (lactic acid) 3D scaffolds. In: Microscopy and imaging science: Practical approaches to applied research and education. Méndez-Vilas A (ed). Formatex Research Center, Barcelona, pp260-264, 2017.

30. Murphy AR, Laslett A, O'Brien CM and Cameron NR: Scaffolds for $3 \mathrm{D}$ in vitro culture of neural lineage cells. Acta Biomater 54: 1-20, 2017.

31. O'Connor SM, Stenger DA, Shaffer KM, Maric D, Barker JL and Ma W: Primary neural precursor cell expansion, differentiation and cytosolic $\mathrm{Ca}(2+)$ response in three-dimensional collagen gel. J Neurosci Methods 102: 187-195, 2000.

32. Seidlits SK, Khaing ZZ, Petersen RR, Nickels JD, Vanscoy JE, Shear JB and Schmidt CE: The effects of hyaluronic acid hydrogels with tunable mechanical properties on neural progenitor cell differentiation. Biomaterials 31: 3930-3940, 2010.

33. Mannella GA, Carfì Pavia F, Conoscenti G, La Carrubba V and Brucato V: Evidence of mechanisms occurring in thermally induced phase separation of polymeric systems. J Polym Sci Part B Polym Phys 52: 979-983, 2014

34. Schiera G, Bono E, Raffa MP, Gallo A, Pitarresi GL, Di Liegro I and Savettieri G: Synergistic effects of neurons and astrocytes on the differentiation of brain capillary endothelial cells in culture. J Cell Mol Med 7: 165-170, 2003.

35. Carfî Pavia F, Conoscenti G, Greco S, La Carrubba V, Ghersi G and Brucato V: Preparation, characterization and in vitro test of composites poly-lactic acid/hydroxyapatite scaffolds for bone tissue engineering. Int J Biol Macromol 119: 945-953, 2018.

36. Liverani C, Mercatali L, Cristofolini L, Giordano E, Minardi S, Porta GD, De Vita A, Miserocchi G, Spadazzi C, Tasciotti E, et al: Investigating the mechanobiology of cancer cell-ECM interaction through collagen-based 3D scaffolds. Cell Mol Bioeng 10: 223-234, 2017.

37. Villalona GA, Udelsman B, Duncan DR, McGillicuddy E, Sawh-Martinez RF, Hibino N, Painter C, Mirensky T, Erickson B, Shinoka $\mathrm{T}$ and Breuer CK: Cell-seeding techniques in vascular tissue engineering. Tissue Eng Part B Rev 16: 341-350, 2010.

38. Proia P, di Liegro CM, Schiera G, Fricano A and Di Liegro I: Lactate as a metabolite and a regulator in the central nervous system. Int J Mol Sci 17: pii: E1450, 2016.

39. Giaume C, Koulakoff A, Roux L, Holcman D and Rouach N: Astroglial networks: A step further in neuroglial and gliovascular interactions. Nat Rev Neurosci 11: 87-99, 2010.

40. Pannasch U and Rouach N: Emerging role for astroglial networks in information processing: From synapse to behavior. Trends Neurosci 36: 405-417, 2013 
41. Bosone C, Andreu A and Echevarria D: GAP junctional communication in brain secondary organizers. Dev Growth Differ 58: 446-455, 2016

42. Frohlich D, Kuo WP, Fruhbeis C, Sun JJ, Zehendner CM, Luhmann HJ, Pinto S, Toedling J, Trotter J and Krämer-Albers EM: Multifaceted effects of oligodendroglial exosomes on neurons: impact on neuronal firing rate, signal transduction and gene regulation. Philos Trans R Soc Lond B Biol Sci 369: 20130510, 2014.

43. Carfì-Pavia F, Turturici G, Geraci F, Brucato V, La Carrubba V, Luparello C and Sconzo G: Porous poly (L-lactic acid) scaffolds are optimal substrates for internal colonization by A6 mesoangioblasts and immunocytochemical analyses. J Biosci 34: 873-879, 2009

44. Ma SH, Lepak LA, Hussain RJ, Shain W and Shuler ML: An endothelial and astrocyte co-culture model of the blood-brain barrier utilizing an ultra-thin, nanofabricated silicon nitride membrane. Lab Chip 5: 74-85, 2005.

45. Frühbeis C, Fröhlich D, Kuo WP and Krämer-Albers EM Extracellular vesicles as mediators of neuron-glia communication. Front Cell Neurosci 7: 182, 2013.

46. Zagrean AM, Hermann DM, Opris I, Zagrean L and PopaWagner A: Multicellular crosstalk between exosomes and the neurovascular unit after cerebral ischemia. Therapeutic implications. Front Neurosci 12: 811, 2018.
47. Balusu S, Van Wonterghem E, De Rycke R, Raemdonck K, Stremersch S, Gevaert K, Brkic M, Demeestere D, Vanhooren V, Hendrix A, et al: Identification of a novel mechanism of blood-brain communication during peripheral inflammation via choroid plexus-derived extracellular vesicles. EMBO Mol Med 8: 1162-1183, 2016

48. Basso $\mathrm{M}$ and Bonetto V: Extracellular vesicles and a novel form of communication in the brain. Front Neurosci 10: 127, 2016

49. O'Brien FJ: Biomaterials and scaffolds for tissue engineering. Mater Today 14: 88-95, 2011.

50. Tajbakhsh S and Hajiali F: A comprehensive study on the fabrication and properties of biocomposites of poly(lactic acid)/ceramics for bone tissue engineering. Mater Sci Eng C Mater Biol Appl 70: 897-912, 2017.

This work is licensed under a Creative Commons Attribution-NonCommercial-NoDerivatives 4.0 International (CC BY-NC-ND 4.0) License. 